GASTRIC CANCER

\title{
Association of interleukin 1B gene polymorphism and gastric cancers in high and low prevalence regions in China
}

\author{
Z-R Zeng, P-J Hu, S Hu, R-P Pang, M-H Chen, M Ng, J J Y Sung
}

See end of article for authors' affiliations

Correspondence to: Professor P J Hu, First Affiliated Hospital of Sun Yat-sen University of Medical Sciences,

Guangzhou, 510080, PR China; pihumd@ vip.163.com

Accepted for publication 9 June 2003

\begin{abstract}
Aim: Our aim was to study the relationship between interleukin 1B (IL-1B) polymorphism, Helicobacter pylori infection, and gastric cancer in high prevalent (Shanxi) and low prevalent (Guangdong) regions in China.

Method: Genomic DNA was extracted from peripheral blood of 192 healthy volunteers, 84 gastric cancer patients from Guangdong and 169 healthy volunteers, and 86 gastric cancer patients from Shanxi. Polymorphisms in IL- IB that encodes IL- $1 \beta$ and IL- IRN that encodes IL- 1 receptor antagonist were analysed by polymerase chain reaction-restriction fragment length polymorphism (PCR-RFLP). These polymorphic sites include promoter regions of IL- IB at positions $+3954,-511$ (C-T transition), and -31 (T-C transition), and IL-IRN variable tandem repeats.

Results: In the low prevalence region, the frequencies of the IL- $1 B+3954 \mathrm{~T} / \mathrm{T}$ and IL- $1 R N{ }^{*} 2 /{ }^{*} 2$ genotypes were similar. IL-1B $-511 \mathrm{~T} / \mathrm{T}$ genotype frequency was significantly higher among patients with gastric cancer $(25.0 \%)$ than control subjects $(12.5 \%)\left(\chi^{2}=6.7, p=0.01\right)$. In the high prevalence region, the frequencies of the $I L-1 B+3954 T / T$ and $-511 T / T$ genotypes and the $I L-1 R N * 2 /{ }^{*} 2$ genotype in the cancer and control groups were similar. IL- $1 B-31 C / C$ genotype frequency was significantly higher among patients with gastric cancer $(90.0 \%)$ than controls $(78.0 \%)\left(\chi^{2}=5.0, p=0.025\right)$. Compared with the low prevalence region, control subjects from the high prevalence region had a higher frequency of the IL-1B $-511 \mathrm{~T} / \mathrm{T}$ genotype $\left(23.0 \%\right.$ v $\left.12.5 \% ; \chi^{2}=7.0, \mathrm{p}<0.008\right)$. While $H$ pylori infection alone had only a modest effect on the risk of gastric cancer development (odds ratio (OR) 5.0 (95\% confidence interval (Cl) 1.5-16.3)), combined with the IL-1B - 511T/T genotype the risk was markedly elevated (OR 17.1, 95\% CI 3.8-76.4).

Conclusion: IL- $1 B-511 \mathrm{~T} / \mathrm{T}$ genotypes are associated with gastric cancer in China. The effect of IL-1B polymorphism is less obvious in areas of high prevalence for gastric cancer.
\end{abstract}

$H$ elicobacter pylori infection causes a wide spectrum of gastric pathologies, from asymptomatic gastritis and peptic ulcer disease to gastric malignancies. The rationale for this divergent clinical outcome is gradually unveiled in the paradigm of the two way interaction between acid secretion and $H$ pylori induced gastritis. ${ }^{1}$ The acid secreting capacity of the stomach is crucial in determining outcome: a high acid secretor with antral predominant gastritis tends to develop peptic ulcers whereas a low secretor with pangastritis tends to develop gastric cancer.

Recently, the interleukin (IL)- $1 B$ gene has been proposed as a key factor in determining the pattern of gastritis and risk of malignant transformation. ${ }^{2}$ IL- $1 \beta$, induced by $H$ pylori infection, is known to be a strong proinflammatory cytokine as well as a strong inhibitor of acid secretion in the stomach. IL- 1 gene cluster ( $I L-I B$ encoding $I L-1 \beta$ and $I L-I R N$ encoding the $I L-I$ receptor antagonist) has a number of functionally relevant polymorphisms that could be correlated with high or low IL-1 $\beta$ production. ${ }^{3}$ El-Omar et al first reported that genotypes $I L-1 B-511 \mathrm{~T}+/-31 \mathrm{C}+$ and $I L-I R N^{*} 2 /{ }^{*} 2$ are associated with an increased risk of gastric cancer development. ${ }^{4}$ Their findings in Scottish and Polish patients were subsequently confirmed by studies in other ethnic groups from the USA $^{5}$ and Portugal. ${ }^{6}$ In Machado et al's study, the association between proinflammatory IL-1 genotypes and gastric cancer was confined to the intestinal type with only a nonsignificant risk being shown for the diffuse type. ${ }^{6}$ Furthermore, in a Japanese study, proinflammatory $I L-I B$ polymorphisms were also found to be associated with hypochlorhydria and atrophic gastritis, a precancerous lesion in the stomach. ${ }^{7}$ These abnormalities were correlated with reduction in serum pepsinogen I/II ratio which has been established as a surrogate marker of gastric atrophy. The host genetic makeup and bacterial genotypes were investigated in first degree relatives of the Scottish gastric cancer cohort. Atherton et al reported that putative high output $I L-I B$ genotypes and vacA $s 1 / \mathrm{mlH}$ pylori type are independently associated with hypochlorhydria and gastric atrophy. ${ }^{8}$

It is known that gastric cancer is prevalent in the northern part of China whereas peptic ulcer disease is more common in the south. ${ }^{9}$ Factors such as the prevalence of $H$ pylori infection and environmental factors, including diet and smoking, have been implicated in the different disease patterns. In the present study, we investigated the genotype of gastric cancer patients and healthy volunteers in two regions of China with different prevalence rates of gastric cancer.

\section{METHOD}

\section{Subjects}

Two provinces were chosen in this study to represent areas of high prevalence (Shanxi) and low prevalence (Guangdong) for gastric cancer in China. Their mean annual gastric cancer mortality is approximately 23.6 and $7.9 / 100000$ population. ${ }^{910}$ In Guangdong, a total of 276 subjects were studied. This included 84 patients with histologically confirmed noncardiac gastric cancer and 192 healthy volunteers from the Sun Yat-sen University of Medical Sciences. In Shanxi

Abbreviations: IL, interleukin; PCR-RFLP, polymerase chain reactionrestriction fragment length polymorphism; OR, odds ratio 


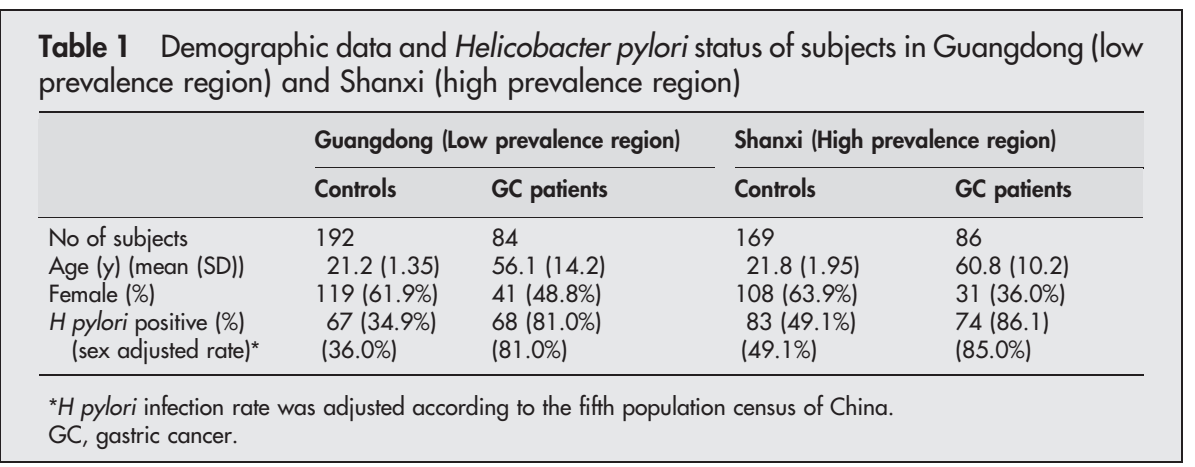

province, 86 patients with non-cardiac gastric cancer and 169 healthy volunteers from Xian Medical University were recruited into the study. Age and sex of the patients are shown in table 1 . All subjects included in this study belonged to the ethnic group of Han. None of these subjects had a history of systemic lupus erythematosis, diabetes mellitus, rheumatoid arthritis, or inflammatory bowel disease. Subjects with a family history of gastric cancer were also excluded.

\section{Evaluation of $\boldsymbol{H}$ pylori prevalence}

$H$ pylori status of subjects was determined by an ELISA assay for anti-H pylori IgG (BioChek Inc., USA). All analyses were done in duplicate and with an internal standard. Concentrations of $H$ pylori IgG were determined by reading at an optical density of $450 \mathrm{~nm}$. Subjects were considered to be $H$ pylori positive if the concentration exceeded $20 \mathrm{U} / \mathrm{ml}$.

\section{DNA extraction}

DNA was isolated from peripheral blood using the NaI method. Briefly, heparinised whole blood $(100 \mu \mathrm{l})$ was added to equal volumes of $6 \mathrm{M} \mathrm{NaI}$ and chloroform:isoamle alcohol, and centrifuged at $5000 \mathrm{~g}$ for five minutes. The aqueous layer was removed and isopropanol was added to the pellet to deposit DNA (centrifuged at $5000 \mathrm{~g}$ for five minutes). Extracted DNA was rinsed 2 3 times with 70\% alcohol and resuspended in $40 \mu \mathrm{l}$ of TE buffer $(\mathrm{pH} 8.0) .{ }^{11}$

\section{Genotyping of IL-1 polymorphisms}

Polymorphisms in $I L-1 B$ that encodes IL- $1 \beta$ and $I L-I R N$ that encodes IL-1 receptor antagonist were genotyped by polymerase chain reaction-restriction fragment length polymorphism (PCR-RFLP). IL- $I B$ polymorphic sites include the promoter region of $I L-1 B$ at positions $+3954,-511$ (C-T transition), and -31 ( $\mathrm{T}-\mathrm{C}$ transition) (fig $\mathrm{l}$ ).

A fragment containing the AvaI polymorphic site at position -511 of the $I L-1 B$ gene was amplified by PCR. The oligonucleotides 5'-GCCTGAACCCTGCATACCGT-3' and 5'GCCAATAGCCCTCCCTTCT-3' flanking this region were used as primers. PCR conditions were as follows: denaturation at $94^{\circ} \mathrm{C}$ for 10 minutes, followed by $94^{\circ} \mathrm{C}$ ( 30 seconds), $65^{\circ} \mathrm{C}$ (30 seconds), and $72^{\circ} \mathrm{C}$ (30 seconds) for five cycles, $94^{\circ} \mathrm{C}$ (30 seconds), $60^{\circ} \mathrm{C}$ (30 seconds), and $72^{\circ} \mathrm{C}$ (30 seconds) for 30 cycles, followed by $94^{\circ} \mathrm{C}$ ( 30 seconds), $55^{\circ} \mathrm{C}$ ( 30 seconds), and $72^{\circ} \mathrm{C}$ (30 seconds) for five cycles. A final extension was carried out at $72^{\circ} \mathrm{C}$ for seven minutes and cooling down to $4^{\circ} \mathrm{C}$. Fragments were separated by electrophoresis on $3 \%$ agarose with ethidium bromide staining using appropriate commercially available size markers for comparison. The $\mathrm{C}$ allele was designated if two bands of 92 and 63 bp were obtained, and the $\mathrm{T}$ allele was designated if a signal band of the undigested 155 bp was obtained. Genotypes were designated as follows: $\mathrm{C} / \mathrm{C}$, two bands of 92 and $63 \mathrm{bp}: \mathrm{C} / \mathrm{T}$, three bands of 155, 92, and $63 \mathrm{bp}$; and T/T, a single band of $155 \mathrm{bp}$.
A fragment containing the AluI polymorphic site at position -31 of the $I L-1 B$ gene was amplified by PCR. The oligonucleotides 5"-AGAAGCTTCCACCAATACTC-3' and 5'ACCACCTAGTTGTAAGGAAG-3' flanking this region were used as primers. PCR conditions were the same as above. Electrophoresis on 3\% agarose with ethidium bromide staining was used. The $\mathrm{T}$ allele was designated if two bands of 100 and $52 \mathrm{bp}$ were obtained and the $\mathrm{C}$ allele was designated if a single band of the undigested 152 bp was obtained. Genotype were designated as follows: T/T, two bands of 100 and $52 \mathrm{bp}$; C/T, three bands of 152, 100, and 52 $\mathrm{bp}$; and $\mathrm{T} / \mathrm{T}$, a single band of $100 \mathrm{bp}$.

A fragment containing the TaqI polymorphic sites at position +3954 of the $I L-1 B$ gene was amplified by PCR. The oligonucleotides 5'-AATTTTGCCACCTCGCCTCA-3' and 5'-CGGAGCGTGCAGTTCAGTGAT-3' flanking this region were used as primers. PCR conditions were the same as above. Electrophoresis on 3\% agarose with ethidium bromide staining was used. The $\mathrm{C}$ allele was designated if two bands of 88 and $64 \mathrm{bp}$ were obtained and the $\mathrm{T}$ allele was designated if a single band of undigested 152 bp was obtained. Genotypes were designated as follows: C/C, two
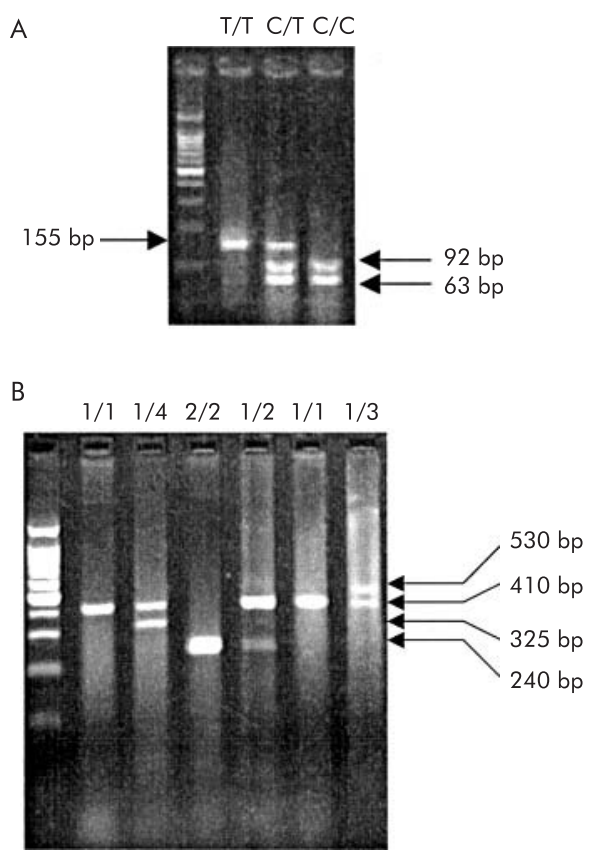

Figure 1 Genotyping of the IL-1B 51 IC/T and IL-1RN variable number of tandem repeats polymorphism. (A) Polymerase chain reactionrestriction fragment length polymorphism (PCR-RFLP) agarose gel electrophoresis of the IL-IB 511C/T polymorphism showing the $C / T$, $C / C$, and T/T genotypes. (B) PCR-RFLP agarose gel electrophoresis of the IL-1RN variable number of tandem repeats polymorphism illustrating the most commonly studied genotypes. 
Table 2 IL-1B genotype frequencies in control subjects and gastric cancer (GC) patients in Guangdong (low prevalence region) and Shanxi (high prevalence region)

\begin{tabular}{|c|c|c|c|c|c|}
\hline \multirow[b]{2}{*}{ Genotype } & & \multicolumn{2}{|c|}{ Guangdong (low prevalence region) } & \multicolumn{2}{|c|}{ Shanxi (high prevalence region } \\
\hline & & $\begin{array}{l}\text { Controls } \\
\text { (n= 192) }\end{array}$ & $\begin{array}{l}\text { GC patients } \\
(n=84)\end{array}$ & $\begin{array}{l}\text { Controls } \\
(n=169)\end{array}$ & $\begin{array}{l}\text { GC patients } \\
(n=86)\end{array}$ \\
\hline \multirow[t]{4}{*}{$I L-1 B-511$} & $\mathrm{C} / \mathrm{C}$ & 87 & 18 & 34 & 19 \\
\hline & $\mathrm{C} / \mathrm{T}$ & 78 & 45 & 97 & 45 \\
\hline & $\mathrm{T} / \mathrm{T}$ & $27(14.1 \%)$ & $21(25.0 \%)$ & $38(22.5 \%)$ & $22(25.6 \%)$ \\
\hline & Sex adjusted $T / T$ & $(12.5 \%)$ & $(25.0 \%)^{*}$ & $(23.0 \%) \ddagger$ & $(23.1 \%)$ \\
\hline \multirow[t]{4}{*}{$\mid L-1 B-31$} & $\mathrm{C} / \mathrm{C}$ & $156(81.3 \%)$ & $54(64.3 \%)$ & $128(75.7 \%)$ & $78(90.7 \%)$ \\
\hline & Sex adjusted $C / C$ & $(82.1 \%)$ & $(64.3 \%) \dagger$ & $(78.0 \%)$ & $(90.0 \%) \S$ \\
\hline & $\mathrm{C} / \mathrm{T}$ & 35 & 27 & 34 & 4 \\
\hline & $\mathrm{T} / \mathrm{T}$ & 1 & 3 & 7 & 4 \\
\hline \multirow[t]{3}{*}{$I L-B+3954$} & $\mathrm{C} / \mathrm{C}$ & 164 & 77 & 152 & 77 \\
\hline & $\mathrm{C} / \mathrm{T}$ & 28 & 7 & 17 & 8 \\
\hline & $\mathrm{T} / \mathrm{T}$ & 0 & 0 & 0 & 1 (1.2\%) \\
\hline \multicolumn{6}{|c|}{$\begin{array}{l}{ }^{*}{ }^{*}{ }_{\text {Cancer }} \text { Guangdong versus control } \\
\text { †Cancer } \\
\text { Guangdong versus control }\end{array}$} \\
\hline
\end{tabular}

Table 3 IL-1RN genotype frequencies in control subjects and gastric cancer (GC) patients in Guangdong (low prevalence region) and Shanxi (high prevalence region)

\begin{tabular}{|c|c|c|c|c|c|}
\hline \multirow[b]{2}{*}{ Genotype } & & \multicolumn{2}{|c|}{ Guangdong (low prevalence region) } & \multicolumn{2}{|c|}{ Shanxi (high prevalence region) } \\
\hline & & $\begin{array}{l}\text { Controls } \\
(\mathrm{n}=192)\end{array}$ & $\begin{array}{l}\text { GC patients } \\
(n=84)\end{array}$ & $\begin{array}{l}\text { Controls } \\
(n=169)\end{array}$ & $\begin{array}{l}\text { GC patients } \\
(\mathrm{n}=86)\end{array}$ \\
\hline \multirow[t]{6}{*}{ IL-IRN } & ${ }^{*} 1 /{ }^{*} 1$ & 175 & 74 & 161 & 76 \\
\hline & ${ }^{*} 1 /{ }^{*} 2$ & 13 & 8 & 4 & 9 \\
\hline & $* 2 / * 2$ & 2 & 0 & 2 & 1 \\
\hline & $* 1 / * 3$ & 2 & 0 & 1 & 0 \\
\hline & ${ }^{*} 1 / * 4$ & 0 & 1 & 1 & 0 \\
\hline & $* 2 /{ }^{*} 4$ & 0 & 1 & 0 & 0 \\
\hline \multirow[t]{4}{*}{$I L-I R N$} & $\mathrm{~L} / \mathrm{L}$ & 177 & 75 & 163 & 76 \\
\hline & $\mathrm{L} /{ }^{*} 2$ & 13 & 9 & 4 & 9 \\
\hline & $* 2 /{ }^{*} 2$ & $2(1.0 \%)$ & 0 & $2(1.2 \%)$ & $1(1.2 \%)$ \\
\hline & Sex adjusted $* 2 /{ }^{*} 2$ & $(1.1 \%)$ & & $(0.9 \%)$ & $(1.6 \%)$ \\
\hline
\end{tabular}

bands of 88 and $64 \mathrm{bp}$; C/T, three bands of 152, 88, and $64 \mathrm{bp}$; and $\mathrm{T} / \mathrm{T}$, a single band of $152 \mathrm{bp}$.

The IL-RN gene has a penta-allelic 86 base pair tandem repeat polymorphism (variable number of tandem repeats). The less common allele $2\left(I L-l R N^{*} 2\right)$ is associated with enhanced IL- $1 \beta$ production and a wide range of chronic inflammatory and autoimmune conditions. The IL-RN polymorphism was analysed by PCR that amplifies the tandem repeat regions, as described previously. $^{4}$ Oligonucleotides 5' -CCCCTCAGCAACACTCC-3'

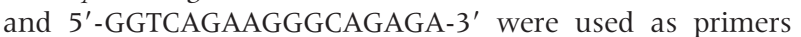
in the PCR. The PCR conditions were the same as above. PCR products were sized by electrophoresis on a $2 \%$ agarose gel stained with ethidium bormide. Alleles were sized relative to a $100 \mathrm{bp}$ DNA ladder and coded as follows: allele $\mathrm{l}=410 \mathrm{bp}$ (four repeats), allele $2=240 \mathrm{bp}$ (two repeats), allele $3=530$ bp (five repeats), allele $4=325$ bp (three repeats), and allele $5=595$ bp (six repeats). These alleles were then classified as short (allele $2 *=* 2$ ) or long (alleles $* 1, * 3, * 4$ and $* 5=\mathrm{L}$ ). The genotyping patterns were classified as $\mathrm{L} / \mathrm{L}, \mathrm{L} / * 2$, and $* 2 / * 2$ in accordance with the recent report by Machado and colleagues. ${ }^{6}$

\section{Statistical analysis}

The sex difference in the two populations was adjusted according to the fifth population census of China. ${ }^{12}$ The Hardy-Weinberg equilibrium at individual loci was assessed by $\chi^{2}$ statistics using the program SPSS (version 10.1, Chicago, Illinois, USA). Comparison of genotype frequencies between cases and controls was assessed by $\chi^{2}$ statistics. The effect of the $I L-1 B-511 \mathrm{~T}$ allele on the risk of gastric cancer was expressed as odds ratios (OR) with 95\% confidence interval (CI). All p values were two sided, and only values $<0.05$ were considered statistically significant.

\section{RESULTS}

Mean age and sex of the gastric cancer patients and control subjects are shown in table 1 . As the control subjects were medical students from Sun Yat-sen University of Medical Sciences and Xian Medical University, their ages were much lower than those of the gastric cancer patients. There was also a predominance of females in the control groups.

The frequencies of genotypes $I L-I B$ and $I L-I R N$ are summarised in tables 2 and 3 , respectively. In the low

Table 4 Allele frequency of $I L-1 B-511$ and IL- $1 B-31$ in low prevalence and high prevalence regions for gastric cancer

\begin{tabular}{lll}
\hline $\begin{array}{l}\text { Allele linkage } \\
\text { (IL-1B-511/-31) }\end{array}$ & $\begin{array}{l}\text { Non-cancer subjects in } \\
\text { low prevalence region } \\
(\mathbf{n}=192)\end{array}$ & $\begin{array}{l}\text { Non-cancer subjects in } \\
\text { high prevalence region } \\
(\mathbf{n}=169)\end{array}$ \\
\hline C-C & 0.61 & 0.44 \\
C-T & 0.05 & 0.04 \\
T-C & 0.32 & 0.46 \\
T-T & 0.02 & 0.06 \\
\hline
\end{tabular}


prevalence region for gastric cancer (Guangdong), there was no difference in the frequencies of the $I L-I B+3954 \mathrm{~T} / \mathrm{T}$ and $I L$ $I R N * 2 / * 2$ genotypes between gastric cancer patients and controls. The $I L-I R N * 2 / * 2$ genotype was not found in any gastric cancer patient in this region. The $I L-1 B-511 \mathrm{~T} / \mathrm{T}$ genotype was significantly more frequent in gastric cancer patients $(25.0 \%)$ compared with controls $(12.5 \%)\left(\chi^{2}=6.7\right.$, $\mathrm{p}=0.01)$. The risk of developing gastric cancer with this genotype was significantly increased (OR 2.3, 95\% CI 1.24.5). In this cohort, the prevalence of the $I L-1 B-31 \mathrm{C} / \mathrm{C}$ genotype in control subjects was significantly higher than that in gastric cancer patients $\left(82.1 \% \quad v \quad 64.3 \% ; \chi^{2}=9.9\right.$, $\mathrm{p}=0.002)$.

Unlike the findings in the low prevalence region, the high prevalence region showed no difference in the distribution of $I L-1 B+3954 \mathrm{~T} / \mathrm{T},-511 \mathrm{~T} / \mathrm{T}$, or $I L-1 R N$ genotype between gastric cancer patients and controls. The $I L-I R N * 2 / * 2$ genotype was found in only one gastric cancer patient (1.2\%) and two control subjects (1.2\%). The $I L-1 B-511 \mathrm{~T} / \mathrm{T}$ genotype was found in $23.1 \%$ of gastric cancer patients and $23.0 \%$ of control subjects. There was no difference in the frequency of this proinflammatory genotype between the two groups $\left(23.1 \% \quad v \quad 23.0 \% ; \chi^{2}=0.02, \quad \mathrm{p}=0.89\right)$. Comparing control subjects in high prevalence versus low prevalence regions for gastric cancer, the frequency of the $I L-1 B-511 \mathrm{~T} /$ $\mathrm{T}$ genotype was significantly higher in the former $(23.0 \% \mathrm{v}$ $\left.12.5 \% ; \chi^{2}=7.0, p=0.008\right)$. However, the prevalence of the $I L-I B-31 C / C$ genotype in gastric cancer patients in the high prevalence region was significantly higher than that of control subjects $\left(90.0 \% \vee 78.0 \% ; \chi^{2}=5.0, p=0.025\right)$.

As $I L-1 B-511$ and $I L-1 B-31$ show differences in frequencies between cancer patients and control subjects and between high prevalence and low prevalence regions, we tested linkage disequilibrium for the two polymorphisms in the two study regions. The results are summarised in table 4 and show that for the $I L-1 B-511$ and -31 genotypes there was no evidence of linkage disequilibrium in both the high prevalence and low prevalence regions $\left(\mathrm{D}^{\prime}=0.08\right.$ and 0.11 ; $\chi^{2}=2.12$ and $\left.4.14, p>0.05\right)$. The two genotypes were independent risk factors for gastric carcinogenesis in both regions.

The prevalence of $H$ pylori infection in the two regions is given in table 1. In the low prevalence region of Guangdong, patients with gastric cancer had significantly higher rates of infection compared with controls $\left(81.0 \% v 36.0 \% ; \chi^{2}=49.6\right.$, $\mathrm{p}<0.001$, OR $7.93,95 \%$ CI 4.27-14.74). The same was true for the high prevalence region of Shanxi where $H$ pylori infection was more common among patients with gastric cancer than controls $\left(85.0 \% \vee 49.1 \% ; \chi^{2}=32.9, \mathrm{p}<0.001\right.$, OR 6.39, 95\% CI 3.24-12.62). As genotype IL-1B - $511 \mathrm{~T} / \mathrm{T}$ appears to have the most consistent association with gastric cancer, analysis of the cancer risk in relation to $H$ pylori infection and this genotype was performed (tables 5, 6). In the low prevalence area for gastric cancer, using non-infected (H pylori-) cases and $\mathrm{T} / \mathrm{T}$ genotype as the reference group, the risk of gastric cancer in the non-infected and $\mathrm{T} / \mathrm{T}$ genotype was not significantly raised $\left(\chi^{2}=0.7, p=0.4\right)$. However, in the presence of $H$ pylori infection, the $\mathrm{C} / \mathrm{C}$ genotype had an increased risk of developing gastric cancer $\left(\chi^{2}=7.9\right.$, $\mathrm{p}=0.005)$. The risk of cancer development was dramatically increased for the $\mathrm{T} / \mathrm{T}$ genotype with $H$ pylori infection $\left(\chi^{2}=16.9, \mathrm{p}<0.001\right.$, OR 17.1, 95\% CI 3.8-76.4). In the high prevalence region, the non-infected $\mathrm{T} / \mathrm{T}$ genotype did not have a significantly increased risk of gastric cancer $\left(\chi^{2}=1.1\right.$, $\mathrm{p}=0.29)$. H pylori infection in the $\mathrm{C} / \mathrm{C}$ genotype had a significantly raised risk of gastric cancer $\left(\chi^{2}=13.3, \mathrm{p}<0.001\right.$, OR 22.8, 95\% CI 2.7-190.8). H pylori infection in the $\mathrm{T} / \mathrm{T}$ genotype also had a significantly increased risk of gastric cancer $\left(\chi^{2}=6.1, p=0.014\right.$, OR 5.0, 95\% CI 1.3-20.3).

\section{DISCUSSION}

Gastric cancer, like many malignancies, is a result of interaction between genetic factors of the host together with dietary and other factors in the environment. Epidemiological studies on Northern Chinese and American Japanese in Hawaii lent strong support to the effects of lack of fresh fruit and vegetable, smoking, and consumption of salty food in the development of gastric cancer. ${ }^{13}{ }^{14}$ In the last decade, much attention has been focused on the role of $H$ pylori infection in the development of the disease. Correa, in his multistep multifactorial model of gastric carcinogenesis, has proposed that $H$ pylori plays a pivotal role in triggering chronic inflammation of the stomach leading to stepwise development of the malignancy. ${ }^{15}$ Recently, a host genetic factor, $I L-I B$ polymorphism, has been added as the last piece in the jigsaw of gastric carcinogenesis. The biological effects of IL- $1 \beta$ as a potent proinflammatory cytokine and inhibitor of acid suppression fits with Correa's model. In the landmark study by El-Omar et al, the estimated odds ratios for individuals having the $I L-1 B-511 \mathrm{~T}+/-31 \mathrm{C}+$ and $I L-1 R N * 2 /$ *2 genotypes of developing gastric cancer were 1.6 and 2.9, respectively. ${ }^{4}$ This finding was subsequently confirmed in other ethnic groups in the USA and Europe. ${ }^{5} 6$

In contrast with studies in Western countries, the relationship between IL-1B polymorphism and gastric cancer has been less clearcut in studies from Asia. In Korea, Ryu et al reported that $I L-I B$ polymorphisms at loci -511 and -31 were not associated with $H$ pylori infection and the risk of gastric cancer. ${ }^{16}$ Furuta et al reported that the $I L-1 B-511$ genotype was associated with high gastric juice $\mathrm{pH}$ in $\mathrm{H}$ pylori infected subjects but the effects of the $I L-I R N$ polymorphism were insignificant. ${ }^{7}$ They also reported that the allele 2 gene was extremely uncommon in Japanese. Kato et al failed to demonstrate a positive association between the $I L-1 B-511 \mathrm{C}$ allele and gastric cancer in their Japanese cohort of 699 subjects. ${ }^{17}$

In our study, we chose Shanxi and Guangdong to represent areas of high prevalence and low prevalence of gastric cancer

Table 5 Odds ratio (OR) of developing gastric cancer according to IL-1B - 511 genotypes and Helicobacter pylori status in Guangdong (low prevalence region)

\begin{tabular}{lllllll}
\hline $\begin{array}{l}\text { H pylori } \\
\text { status }\end{array}$ & IL- IB-511 & $\begin{array}{l}\text { Control } \\
(\mathbf{n}=192)\end{array}$ & $\begin{array}{l}\text { Cancer } \\
(\mathbf{n}=\mathbf{8 4})\end{array}$ & $\chi^{2}$ & $\mathbf{p}$ Value & OR (95\% Cl) \\
\hline H pylori- & $\mathrm{C} / \mathrm{C}$ & 51 & 4 & & & \\
\multirow{2}{*}{ H pylorit } & $\mathrm{T} / \mathrm{T}$ & 20 & 3 & 0.7 & $0.4^{*}$ & $\mathrm{NS}$ \\
& $\mathrm{C} / \mathrm{C}$ & 36 & 14 & 7.9 & $0.005 \dagger$ & $5.0(1.5-16.3)$ \\
& $\mathrm{T} / \mathrm{T}$ & 7 & 18 & 16.9 & $<0.001 \ddagger$ & $17.1(3.8-76.4)$ \\
\hline
\end{tabular}

${ }^{*}$ Cancer $_{H p-T / T}$ versus control $H_{\mathrm{H}-\mathrm{T} / \mathrm{T}}: \chi^{2}=0.7, \mathrm{p}=0.4$.

+Cancer ${ }_{H p+} \mathrm{C} / \mathrm{C}$ versus control $\mathrm{Hp}_{\mathrm{C}} \mathrm{C} / \mathrm{C}: \chi^{2}=7.9, \mathrm{p}=0.005, \mathrm{OR} 5.0,95 \% \mathrm{Cl} 1.5-16.3$.

‡Cancer $_{H p+T / T}$ versus Control Hp+ T/T $_{1}: \chi^{2}=16.9, \mathrm{p}<0.001$, OR 17.1, 95\% Cl 3.8-76.4 
Table 6 Odds ratio (OR) of developing gastric cancer according to IL-1B -511 genotypes and Helicobacter pylori status in Shanxi (high prevalence region)

\begin{tabular}{llllcrl}
\hline $\begin{array}{c}\text { H pylori } \\
\text { status }\end{array}$ & IL-1B-511 & $\begin{array}{l}\text { Control } \\
(\mathbf{n}=\mathbf{1 6 9 )}\end{array}$ & $\begin{array}{l}\text { Cancer } \\
(\mathbf{n}=\mathbf{8 6})\end{array}$ & $\chi^{\mathbf{2}}$ & $\mathbf{p}$ Value & OR (95\% Cl) \\
\hline H pylori- & $\mathrm{C} / \mathrm{C}$ & 19 & 1 & & & \\
& $\mathrm{~T} / \mathrm{T}$ & 17 & 3 & 1.1 & $0.29^{*}$ & $\mathrm{NS}$ \\
$\mathrm{H}$ pylori+ & $\mathrm{C} / \mathrm{C}$ & 15 & 18 & 13.3 & $<0.001 \dagger$ & $2.7(2.7-190.8)$ \\
& $\mathrm{T} / \mathrm{T}$ & 21 & 19 & 6.1 & $0.014 \ddagger$ & $5.0(1.3-20.3)$ \\
\hline
\end{tabular}

${ }^{*}$ Cancer $_{H p-T / T}$ versus control ${ }_{H p-T / T}: \chi^{2}=1.1, p=0.29$.

+Cancer $H p+C / C$ versus control $H p+C / C: \chi^{2}=13.3, p<0.001$, OR 2.7, 95\% Cl 2.7-190.8.

fCancer $_{H p+} \mathrm{T} / \mathrm{T}$ versus control $\mathrm{H}_{\mathrm{p}+\mathrm{T} / \mathrm{T}}: \chi^{2}=6.1, \mathrm{p}=0.014$, OR 5, 95\% Cl 1.3-20.3.

in China, respectively. There are marked differences in phyla, figures, and hereditary diseases in these two regions. ${ }^{18}$ Their mean annual gastric cancer mortality rates have been estimated as 23.6 and 7.9/100 000 population.

In the present study, the $I L-I B+3954$ polymorphism did not show any correlation with gastric carcinogenesis, which echoes the finding of El-Omar and colleagues. ${ }^{4} I L-1 B-511 \mathrm{~T} / \mathrm{T}$ was found in more than $23 \%$ of gastric cancer patients in both low prevalence and high prevalence regions as well in control subjects in the latter. This is compatible with previous reported in Shangdong, ${ }^{19}$ and the genotype frequency is much higher than that in non-cancer Caucasians. ${ }^{6}$ Furthermore, in the low prevalence region, the $I L-1 B-511 \mathrm{~T} /$ $\mathrm{T}$ genotype was found to increase the risk of gastric cancer development by approximately 2.3 -fold. While the findings in Guangdong province are similar to those reported in the literature, the picture is quite different in Shanxi province, a region of high prevalence for gastric cancer in China. In Shanxi, the frequency of the $I L-1 B-511 \mathrm{~T} / \mathrm{T}$ genotype was equally high in control and gastric cancer patients. The between group difference in the $I L-1 B-511 \mathrm{~T} / \mathrm{T}$ genotype was insignificant. Although allele frequency did not demonstrate the significance of this proinflammatory genotype in gastric carcinogenesis, the high prevalence of this genotype even among non-cancer patients $(23.0 \%)$ may in fact explain the high incidence of this malignancy. Therefore, individuals with proinflammatory genotypes who are also infected with $H$ pylori are expected to have severe hypochlorhydria, atrophy, and therefore a high risk of gastric cancer.

However, there seems to be some confusion about the -31 alleles in the present literature. EI-Omar et al reported that $-31 \mathrm{C}$ alleles increased the risk of gastric cancer (OR 1.9, 95\% CI 1.5-2.6). ${ }^{4}$ In a Japanese study, Takagi et al found that IL$1 \mathrm{~B}$ polymorphisms (IL-1B-511C/C and $-31 \mathrm{~T} / \mathrm{T}$ ) enhanced not only IL- $1 \beta$ production but also IL- 8 production in the gastric body. They believed the above genotypes were associated with $H$ pylori infected gastric mucosal lesions (the development of atrophic gastritis). ${ }^{20}$

In this study, we found that IL-1B-31-C/C genotype frequency was higher in patients with gastric cancer than that in controls in the high prevalence region $(90.0 \% \vee 78.0 \%$; $\chi^{2}=5.0, p=0.025$, OR 2.4, 95\% CI 1.1-5.2). But this genotype frequency was higher in controls than in patients with gastric cancer in the low prevalence region. How do we explain these results? EI-Omar et al considered the IL$1 \mathrm{~B}-31 \mathrm{C}$ allele but not the $\mathrm{T}$ allele as a proinflammatory gene ${ }^{4}$ but the $\mathrm{T}$ allele is the first base of the TATA box in the IL-1B gene promoter. If the IL-1B-31C allele was considered as the proinflammatory allele, IL- $1 \beta$ expression should be upregulated. However, mutation of T to $\mathrm{C}$ in the TATA box in the IL$1 \mathrm{~B}$ gene promoter will result in downregulation of IL-1 $\beta$ expression. Therefore, we believe that the IL-1B-31T allele may be a proinflammatory allele.

Unlike El-Omar's study however we did not find near complete linkage disequilibrium between the two loci. The two genotypes produced almost independent risks for gastric carcinogenesis. A different mode of linkage between $I L$ $1 B-511$ and -31 has also been reported in a study from Korea, indicating that there are multiple forms of linkages possible. $^{16}$

We attempted to study the interaction between $H$ pylori infection and $I L-I B$ genotype polymorphisms. In Guangdong province, $\mathrm{T} / \mathrm{T}$ genotype individuals without $H$ pylori infection did not have an increased risk of gastric cancer. However, the opposite effect was apparent in C/C genotype individuals with $H$ pylori infection. Furthermore, if an infected individual also had the proinflammatory genotype $I L-I B-511 \mathrm{~T} / \mathrm{T}$, the risk of gastric carcinogenesis was dramatically elevated to over 17 fold. This finding suggests that the T/T genotype is not a carcinogenic factor without $H$ pylori infection, and $\mathrm{C} / \mathrm{C}$ genotype individuals infected $H$ pylori also have a cancer risk. But a synergistic effect of the host genetic makeup (IL$1 B-511 \mathrm{~T}$ allele) with $H$ pylori infection may underlie the process of carcinogenesis whereas it is obvious that both $H$ pylori and the $\mathrm{T}$ allele are necessary for the development of gastric cancer. In the high prevalence region, the risk of gastric cancer development in individuals with $H$ pylori infection was substantially increased. The cancer risk also existed in $\mathrm{C} / \mathrm{C}$ genotype individuals with $H$ pylori infection. The presence of the $I L-1 B-511 \mathrm{~T} / \mathrm{T}$ genotype did not appear to further increase the risk of this population. The lack of synergistic effects of these two factors might be related to the low frequency of the $\mathrm{C} / \mathrm{C}$ genotype in this population or the presence of another potent environmental factor, such as dietary habit. We must also point out that analysis of the interaction between $H$ pylori infection and $I L-1 B$ genotype polymorphisms in this study was limited by the differences in mean age and sex between the control subjects and patients with gastric cancer. As the process of $H$ pylori induced malignant transformation in the gastric mucosa takes decades to develop, an age and sex matched control group would provide a better comparison of the cancer risk.

In conclusion, this study confirms that $I L-1 B-511 \mathrm{~T} / \mathrm{T}$ genotypes are associated with an increased risk of gastric carcinoma in China. However, the effect of $I L-1 B$ polymorphism is less obvious in regions with a high prevalence of gastric cancer. The interaction between IL-1B polymorphism and other environmental factors such as $H$ pylori infection and dietary habit deserves further study.

\section{Authors' affiliations}

Z-R Zeng, P-J Hu, S Hu, R-P Pang, M-H Chen, First Affiliated Hospital of Sun Yat-sen University of Medical Sciences, Guangzhou, China

M Ng, J J Y Sung, Chinese University of Hong Kong, Hong Kong

\section{REFERENCES}

1 McColl KE, El-Omar EM, Gillen D. Helicobacter pylori gastritis and gastric physiology. Gastroenterol Clin North Am 2000;29:687-703. 
2 El-Omar EM, Chow WH, Rabkin CS. Gastric cancer and H. pylori: host genetics open the way. Gastroenterology 2001;121:1002-4.

3 Hwang IR, Kodama T, Kikuchi S, et al. Effect of interleukin 1 polymorphisms on gastric mucosal interleukin 1 beta production in Helicobacter pylori infection. Gastroenterology 2002;123:1793-803.

4 El-Omar EM, Carrington M, Chow WH, et al. Interleukin-1 polymorphism associated with increased risk of gastric cancer (erratum appears in Nature 2001;412:99). Nature 2000;404:398-402.

5 El-Omar EM, Chow WH, Gammon MD, et al. Pro-inflammatory genotypes of IL-1B, TNFa and IL-10 increase risk of distal gastric cancer but not of cardia or esophageal adenocarcinoma. Gastroenterology 2001;120(suppl):A86.

6 Machado JC, Pharoah P, Sousa S, et al. Interleukin IB and interleukin IRN polymorophisms are associated with increased risk of gastric carcinoma. Gastroenterology 2001;121:823-9.

7 Furuta T, El-Omar EM, Xiao F, et al. Interleukin $1 \beta$ polymorphisms increase risk of hypochlorhydria and atropic gastritis and reduce risk of duodenal ulcer recurrence in Japan. Gastroenterology 2002; 123:92-105

8 Atherton J, Aviles-Jimenez F, Blaser MJ, et al. Host interleukin- 1 and $\mathrm{H}$. pylori vacA genotypes are independent risk factors for hypochlorhydria and atrophy in gastric cancer relatives. Gastroenterology 2002;122:A170.

9 Chen JS, Campbell TC, Li JY, et al. Diet, life-style and mortality in China. A study of the characteristics of 65 Chinese counties. Oxford: Oxford University Press, 1990

10 Editoral committee for the atlas of cancer mortality in the People's Republic of China. Atlas of cancer mortality in the People's Republic of China. Beijing: China Map Press, 1973
11 Loparev VN, Cartas MA, Monken CE, et al. An efficient and simple method of DNA extraction from whole blood and cell line to identify infectious agents. $J$ Virol Methods 1990;34:105-8.

12 Data from National Bureau of Statistics of China. http://www.stats.gov.cn (accessed 19 August 2003).

13 You WC, Blot WJ, Chang YS, et al. Diet and high risk of stomach cancer in Shandong, China. Cancer Res 1988;48:3518-23.

14 Nomura A, Grove J, Stemmermann G, et al. A prospective study of stomach cancer and its relation to diet, cigarettes, and alcohol consumption. Cancer Res 1990:50:627-31.

15 Correa P. Human gastric carcinogenesis: a multi-step and multi-factorial process. First American Society Award Lecture on Cancer Epidemiology and Prevention. Cancer Res 1992;52:6735-40.

16 Ryu CB, Cheon GJ, Jang JY, et al. Is interleukin-1 polymorphism associated with $\mathrm{H}$. pylori infection and increased risk of gastric cancer? Gastroenterology 2002; 122:T1877.

17 Kato S, Onda M, Yamada S, et al. Association of the interleukin $1 \beta$ genetic polymorphism and gastric cancer in Japanese. J Gastroenterol 2001;36:696-9.

18 Bing-Jian F, Wei H, Yin Yao S. Genome-wide scan for familial nasopharyngeal carcinoma reveals evidence of linkage to chromosome 4. Nat Genet 2002;31:395-9.

19 El-Omar EM, You WC, Chow WH, et al. IL-1 $\beta$ and IL-10 genotypes in a high gastric cancer risk province in China. Gastroenterology 2001;120:A3994.

20 Takagi A, Deguchi R, Kobayashi K, et al. Cytokine expressions and H. pyloriassociated gastric mucosal lesion. Keio J Med 2002;51(suppl 2):51-2. 